\title{
PEMBUATAN KIT SEDERHANA KALORIMETER DARI BAHAN BEKAS BAGI GURU IPA FISIKA
}

\author{
Oleh: \\ Lydia Rohmawati $^{1,1}$, Woro Setyarsih ${ }^{1,2}$, Nugrahani Primary Putri ${ }^{1,3}$ \\ 1Jurusan Fisika, FMIPA, Universitas Negeri Surabaya \\ 1ydiarohmawati@unesa.ac.id \\ worosetyarsih@unesa.ac.id \\ 3 nugrahaniprimary@unesa.ac.id
}

\begin{abstract}
Abstrak
Pembelajaran IPA, peserta didik dituntut secara aktif seperti mengamati, menanya, mengumpulkan data, mengasosiasi, dan mengkomunikasikan di kelas. Namun sarana prasarana laboratorium di SMP Surabaya Selatan diketahui tidak lengkap bahkan ada yang tidak memiliki laboratorium, sehingga pembelajaran di kelas, guru hanya memberikan materi saja. Salah satu materi IPA adalah Termodinamika, khususnya berkaitan dengan alat kalorimeter, yang penerapannya tentang Asas Black. Alat kalorimeter yang ada di pasaran harganya sangatlah mahal, sehingga pelatihan dan pendampingan tentang pembuatan kit sederhana alat kalorimeter dari bahan bekas perlu dilakukan. Pelatihan yang dilakukan terhadap guru MGMP IPA Surabaya Selatan meliputi pembuatan kalorimeter dari bahan bekas, uji coba alat dengan melakukan praktikum, dan pemberian angket berupa respon dan saran terkait dengan pelaksaaan kegiatan pelatihan. Hasil yang diperoleh dari kegiatan ini antara lain pengetahuan dan ketrampilan para guru dalam membuat kit sederhana kalorimeter dari bahan bekas, adanya sikap/respon positif para guru dalam merealisasikan alat tersebut sebagai media pembelajaran di kelas.
\end{abstract}

Kata Kunci: kit, kalorimeter, bahan bekas, laboratorium

\section{Abstract}

Students are actively demanded such as observing, asking questions, collecting data, associating, and communicating mainly in science learning. However, laboratory facilities in South Surabaya Middle School are known incomplete and some do not even have a laboratory, so as the teacher gives the material using the lecture method. One of the science materials is thermodynamics, especially with regard to calorimeter devices, whose application is about Black Principle. The calorimeter equipment on the market is very expensive, so it is necessary to conduct training and assistance on making simple calorimeter tools by waste material. The training carried out on the Surabaya South Science MGMP teachers included making calorimeters by used materials, testing tools by practical training, and giving questionnaires in the form of responses and suggestions related to training activities. The results obtained from this activity included the knowledge and skills of the teachers in making simple calorimeter tools of waste material, and positive attitudes from the teachers to apply the tool as a medium of learning in the classroom.

Keywords: tools, calorimeter, waste material, laboratory

\section{PENDAHULUAN}

Pada kurikulum 2013, seorang guru dituntut untuk mampu mengembangkan kreatifitas dalam mengajar peserta didik terutama dalam pembelajaran IPA. Peserta didik dituntut secara aktif mengamati, menanya dan merumuskan masalah, merumuskan hipotesis, merancang eksperimen, melaksanakan eksperimen, mengumpulkan dan menganalisis data, menarik kesimpulan, serta menyajikan hasil karyanya dalam bentuk presentasi/pemaparan di kelas. Untuk itu, guru IPA harus mampu memfasilitasi peserta didik dalam pembelajaran kooperatif atau kolaboratif, diantaranya membuat alat/kit sederhana dengan memanfaatkan bahanbahan bekas.

Alat ini tidak hanya digunakan sebagai praktikum tetapi dapat digunakan sebagai media pembelajaran di kelas. Salah satu materi IPA adalah termodinamika, berkaitan dengan alat kalorimeter yang penerapannya untuk menjelaskan konsep asas Black. Kit kalorimeter yang ditemui di pasaran harganya relatif mahal, sehingga tidak memungkinkan 
untuk membeli alat ini dalam jumlah yang banyak. Akibatnya dalam pembelajaran IPA, guru jarang memberikan kegiatan praktikum untuk materi kalor. Padahal pada materi tersebut sangat perlu dilakukan kegiatan praktikum, agar peserta didik dapat menganalisa perbedaan temperatur dan kalor jenis dari dua benda/zat yang berbeda. Dalam kegiatan praktikum kalorimeter ini, tidak luput juga digunakan alat ukur massa, berupa neraca pegas.

Berdasarkan pengalaman tahun lalu, para guru dengan latar belakang pendidikan yang berbeda, diketahui ada yang belum paham dan tahu dalam penggunaan neraca pegas. Melalui kegiatan pelatihan pembuatan alat ini, guru selain dilatih membuat alat juga melakukan praktikum dengan variabel tertentu yang ada kaitannya dengan penerapan azas Black sesuai dengan lembar kerja kegiatan yang telah dibuat sambil melatih/mengasah kembali pengetahuan dan ketrampilan membaca alat ukur massa.

Guru MGMP IPA SMP Surabaya Selatan yang ikut serta dalam kegiatan pengabdian di tahun sebelumnya rata-rata belum memiliki sarana dan prasarana laboratorium yang lengkap ataupun belum memiliki laboratorium. Sekolah tersebut antara lain: SMP Tunas Sawunggaling, SMP Hasannudin, SMP AC2, SMP Ma'arif 19, SMP Siti Aminah, SMP Muhamadiyah 6, SMP Muhamadiyah 17, SMP YBPK, SMP Alfalah, MTs Bina Insani, dan SMP Hangtuah 2. Bantuan alat laboratorium dari pemerintah juga terbatas dan itupun biasanya realisasi pengadaan alat juga lama. Adanya kegiatan pengabdian ini, diharapkan memberikan kesempatan bagi para guru IPA khususnya untuk meningkatkan kompetensinya dalam usaha membuat pembelajaran IPA yang berkualitas.

\section{METODE}

Adapun metode pelaksanaan dalan kegiatan pengabdian dilakukan di SMP Aminah Surabaya, antara lain:

a) Persiapan alat dan bahan yang dibutuhkan selama pelatihan, diikuti dengan diskusi dan rencana kegiatan berikutnya. Dalam persiapan ini, alat dan bahannya antara lain: kaleng bekas dengan diameter yang berbeda (kaleng permen dan kaleng rokok), lem kayu, lem besi, fiber/serat, packing sterofoam, termometer, kaki tiga, sumbu kompor, karet elpiji, kasa, botol bekas, dan kawat pengaduk.

b) Pemberian materi termodinamika terutama penggunaan alat kalorimeter yang berhubungan dengan konsep asas Black beserta cara pembuatan alat/kit kalorimeter dari bahan bekas yang sudah disiapkan.

c) Praktik pembuatan kit kalorimeter yang didampingi oleh tim pelaksana kegiatan.

d) Monitoring dan evaluasi kegiatan dengan cara memberikan angket pada peserta pelatihan dan meminta peserta memberikan tanggapan/respon terhadap pertanyaan tentang pelaksanaan pelatihan yang telah dilakukan. Angket yang dibuat terdiri dari 11 pertanyaan tertutup dan 2 pertanyaan terbuka.

\section{HASIL DAN PEMBAHASAN}

Kegiatan pengabdian diawali dengan koordinasi tim pengabdian untuk mengatur agenda persiapan pengadaan alat dan bahan serta pelaksanaan kegiatan di lapangan.

a) Persiapan

Pada tahap persiapan dilakukan pembuatan kit kalorimeter oleh tim pelaksana, dimulai dengan pewarnaan/pengecatan kaleng bekas (fox) menggunakan piloxs. Pengecatan ini dimaksudkan untuk menutupi merk produk kaleng yang digunakan, warna yang dipakai adalah hitam. Setelah itu dilakukan pembuatan desain kalorimeter yang merujuk pada hasil/proyek matakuliah eksperimen, dengan pelapisan menggunakan sterofoam. Pembuatan desain pertama dimulai dari pelapisan kaleng fox dengan bahan lain bukan sterofoam melainkan menggunakan packing sterofoam, dengan alasan lebih mudah dibentuk sesuai dengan ukuran dan bentuk kaleng tanpa harus memotong kecilkecil. Namun kendalanya saat dilakukan uji coba, penggunaan packing tersebut masih ada kebocoran, dimana kaleng permen yang sudah dilapisi bahan tersebut terdapat sisa air, sehingga penggunaan bahan tersebut dianggap gagal. Dengan adanya kegagalan tersebut, dilakukan analisis sebab akibat dan solusi penyelesainnya, yaitu penggunaan sterofoam sebagai pelapis kaleng permen.

Selanjutnya dilakukan pemotongan sterofoam tersebut $\pm 1 \mathrm{~cm}$, dan dibelah menjadi dua, dengan tujuan mempermudah pelepasan kaleng rokok sebagai bejana kalorimeter. Setelah dilapisi sterofoam, kaleng permen tersebut dilapisi kembali 
dengan fiber/serat dan lem kayu, untuk menutupi pori-pori sterofoam kemudian dikeringkan di bawah sinar matahari. Selanjutnya, kaleng permen bagian dalam tersebut dilapisi dengan kain flannel, dengan tujuan sebagai isolator. Untuk kaleng rokok tidak dilapisi dengan bahan lain karena nantinya digunakan untuk mencari kalor jenis kalorimeter.

Terkait dengan tutup kalorimeter, awalnya digunakan tutup kaleng rokok dan dilapisi dengan tutup plastik. Akan tetapi setelah dilakukan uji coba, ternyata alat kalorimeter yang telah dibuat masih dipengaruhi oleh lingkungan luar, dimana tutup kaleng rokok terasa panas dan mengembun di tutup plastik kaleng permen, sehingga saat diukur dengan termometer, suhu yang terukur menunjukkan adanya perubahan suhu yang terlalu cepat. Oleh karena itu, tutup kalorimeter perlu diganti dengan bahan yang benar-benar dapat menjadi penghalang aliran kalor, bukan penyerap kalor, yaitu sterofoam, bahan yang sama dengan pelapis dinding kaleng permen.

Pembuatan tutup kalorimeter dilakukan dengan membuat pola lingkaran yang sesuai dengan ukuran diameter kaleng permen. Bahan sterofoam yang dipilih, memiliki ketebalan sekitar $\pm 10 \mathrm{~cm}$. Setelah itu, dipotong dan dibuat pola lingkaran pada potongan tersebut, sesuai dengan ukuran diameter kaleng rokok, kemudian pada pola lingkaran dalam tersebut, ditancapkan jarum pentul yang melingkar, dengan tujuan agar saat pemotongan nanti (dengan ketentuan tidak dipotong habis melainkan ditipiskan) tepat sesuai dengan ukuran diameter kaleng rokok, sehingga ada pembeda antara diameter dalam dengan diameter luar, membentuk seperti topi. Selanjutnya, dilakukan perekatan sterofoam tersebut ke tutup plastik kaleng permen dengan menggunakan lem kayu, dan dikeringkan pada suhu ruang.

Alat/kit kalorimeter yang telah dibuat dilakukan uji coba dengan memberikan air panas ke dalam bejana kalorimeter (kaleng rokok). Alhasil alat/kit yang dibuat menunjukkan kestabilan suhu, artinya suhu konstan, walaupun hanya bertahan sekitar 2 jam, yang setelah itu alat tersebut memberikan respon terjadinya perubahan suhu yang lambat. Setelah dibandingkan dengan alat yang ada di pasaran, alat yang dibuat tim pengabdian memiliki tingkat presisinya sama dengan yang ada di pasaran malahan alat tim pengabdian tersebut memiliki nilai ekonomis dan ramah lingkungan, yaitu memanfaatkan bahanbahan bekas. Untuk tabung pembakar digunakan botol bekas minuman yang bagian tutup botol tersebut dilubangi sebagai tempat sumbu (penghantar kalor) dan direkatkan dengan baut bekas sepeda, agar saat dinyalakan, api yang terpancar tidak menyebar melainkan fokus satu arah saja sehingga selain aman juga menghemat bahan bakar. Berikut alat/kit kalorimeter yang berhasil dibuat oleh tim pengabdian.

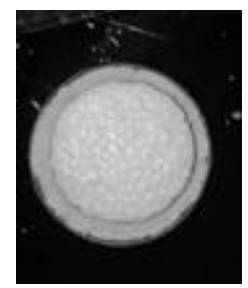

(a)

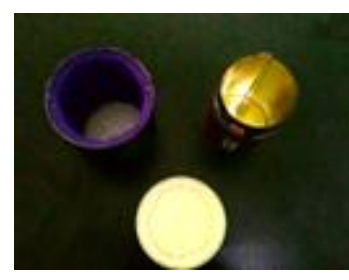

(b)

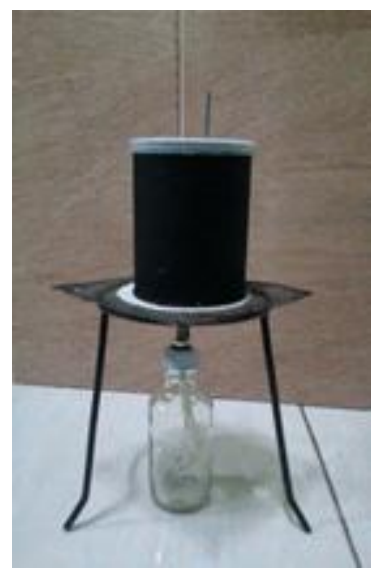

(c)
Gambar 1. Seperangkat alat/kit Termodinamika-Kalorimeter.

(a) tutup Kalorimeter, (b) kalorimeter, (c) Kit kalorimeter

\section{b) Pelaksanaan}

Saat pelaksana kegiatan pengabdian di SMP Aminah Surabaya, peserta pelatihan sangat antusias dalam mengikuti kegiatan pembuatan alat ini, walaupun yang hadir dengan latar belakang pendidikan berbeda (Gambar 2). Setiap langkah pembuatan, tim pengabdian melakukan pendampingan dan pembimbingan pada peserta yang mengalami kesulitan hingga diperoleh sebuah alat/kit kalorimeter. Alat yang berhasil dibuat dilakukan uji coba untuk kegiatan praktikum sesuai dengan lembar kerja kegiatan yang sudah disiapkan oleh tim pengabdian ini. 

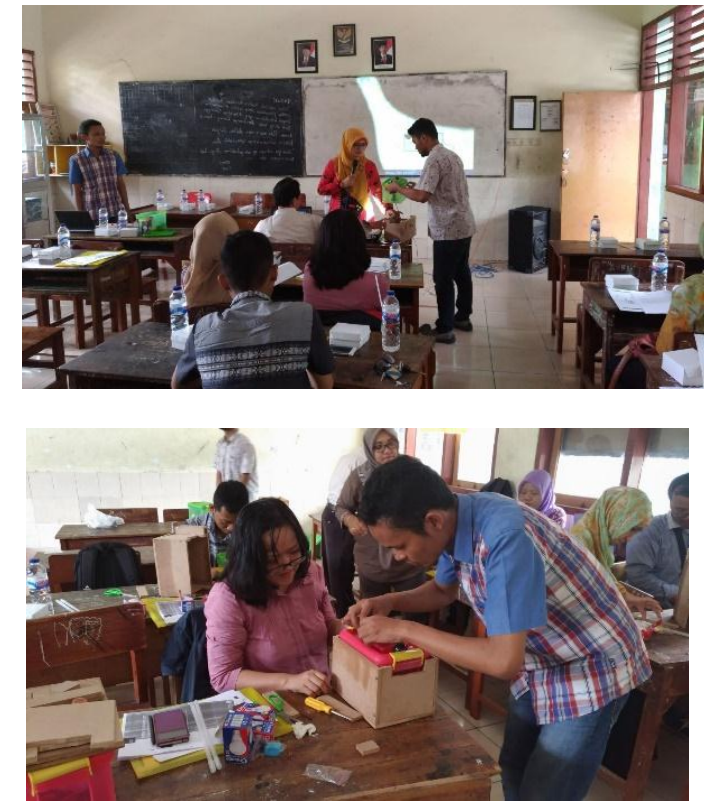

Gambar 2. Pelaksanaan pengabdian c) Monitoring dan evaluasi kegiatan pelatihan Kegiatan ini dilakukan dengan cara memberikan angket pada peserta pelatihan dan meminta peserta memberikan tanggapan/respon terhadap pertanyaanpertanyaan tentang pelaksanaan pelatihan yang telah dilakukan. Angket yang dibuat terdiri dari 11 pertanyaan tertutup dan 2 pertanyaan terbuka. Hasil analisis data angket peserta pelatihan disajikan pada Tabel 1

Tabel 1. Respon peserta pelatihan terhadap materi dan kegiatan pelatihan

\begin{tabular}{|c|c|c|c|}
\hline No. & Pertanyaan & Respon & $\begin{array}{l}\text { Persentase } \\
\text { (\%) }\end{array}$ \\
\hline \multirow[t]{2}{*}{1} & \multirow{2}{*}{$\begin{array}{l}\text { Apakah saat ini Bapak/lbu mengenal dan memahami } \\
\text { (mengerti) semua alat dan bahan yang dibutuhkan untuk } \\
\text { pembuatan Kit Sederhana Termodinamika Kalorimeter? }\end{array}$} & Paham & 78 \\
\hline & & Sangat paham & 22 \\
\hline \multirow[t]{2}{*}{2} & \multirow{2}{*}{$\begin{array}{l}\text { Apakah kini Bapak/lbu merasa kesulitan dalam menyiapkan } \\
\text { semua alat dan bahan yang dibutuhkan untuk pembuatan } \\
\text { Kit Sederhana Termodinamika Kalorimeter? }\end{array}$} & Sedikit sulit & 11 \\
\hline & & Tidak sulit & 89 \\
\hline \multirow[t]{2}{*}{3} & \multirow{2}{*}{$\begin{array}{l}\text { Apakah Bapak/lbu mengikuti dan memahami materi } \\
\text { pembuatan Kit Sederhana Termodinamika Kalorimeter } \\
\text { yang disampaikan oleh tim pelaksana PKM? }\end{array}$} & Sangat paham & 44 \\
\hline & & Paham & 56 \\
\hline \multirow[t]{2}{*}{4} & \multirow{2}{*}{$\begin{array}{l}\text { Apakah Bapak/lbu kini mengalami kesulitan dalam } \\
\text { melakukan sendiri pembuatan Kit Sederhana } \\
\text { Termodinamika Kalorimeter saat tugas diberikan? }\end{array}$} & Sedikit sulit & 11 \\
\hline & & Tidak sulit & 89 \\
\hline \multirow[t]{2}{*}{5} & \multirow{2}{*}{$\begin{array}{l}\text { Apakah Bapak/lbu mengikuti dan memahami bagaimana } \\
\text { cara mengaplikasikan atau menerapkan Kit Sederhana } \\
\text { Termodinamika Kalorimeter dalam } \\
\text { percobaan/demonstrasi? }\end{array}$} & Sangat paham & 33 \\
\hline & & Paham & 67 \\
\hline \multirow[t]{2}{*}{6} & \multirow{2}{*}{$\begin{array}{l}\text { Apakah Bapak/lbu mengalami kesulitan dalam } \\
\text { mengaplikasikan atau menerapkan sendiri Kit Sederhana } \\
\text { Termodinamika Kalorimeter dalam pembelajaran yang } \\
\text { Bapak/lbu lakukan? }\end{array}$} & Sedikit sulit & 33 \\
\hline & & Tidak sulit & 67 \\
\hline \multirow[t]{2}{*}{7} & \multirow{2}{*}{$\begin{array}{l}\text { Bagaimana pandangan bapak/ibu tentang manfaat Kit } \\
\text { Sederhana Termodinamika Kalorimeter dalam pengukuran } \\
\text { dan pembelajaran yang bapak/ibu lakukan? }\end{array}$} & Baik sekali & 67 \\
\hline & & Cukup baik & 33 \\
\hline \multirow[t]{2}{*}{8} & \multirow{2}{*}{$\begin{array}{l}\text { Apa pendapat bapak/ibu terkait pemanfaatan pembuatan } \\
\text { Kit Sederhana Termodinamika Kalorimeter dalam } \\
\text { menunjang dan mendukung pembelajaran Bapak/lbu? }\end{array}$} & Baik sekali & 78 \\
\hline & & Cukup baik & 22 \\
\hline \multirow[b]{2}{*}{9} & \multirow{2}{*}{$\begin{array}{l}\text { Apakah Bapak/lbu merasakan adanya keinginan untuk } \\
\text { mengembangkan pembuatan Kit Sederhana } \\
\text { Termodinamika Kalorimeter sendiri guna menambah } \\
\text { koleksi/perbendaharaan laboratorium dalam usaha } \\
\text { meningkatkan pembelajaran di kelas? }\end{array}$} & Ingin & 33 \\
\hline & & Ingin sekali & 67 \\
\hline \multirow[t]{2}{*}{10} & \multirow{2}{*}{$\begin{array}{l}\text { Apakah kegiatan pelatihan/workshop seperti ini perlu } \\
\text { diadakan lagi kesempatan mendatang }\end{array}$} & Sangat perlu & 78 \\
\hline & & Perlu & 22 \\
\hline
\end{tabular}




\begin{tabular}{|c|c|c|}
\hline No. & Pertanyaan & $\begin{array}{l}\text { Persentase } \\
(\%)\end{array}$ \\
\hline 11 & $\begin{array}{l}\text { Kendala/hambatan apa saja yang dialami selama mengikuti } \\
\text { pelatihan pembuatan Kit Sederhana Termodinamika } \\
\text { Kalorimeter ini }\end{array}$ & $\begin{array}{l}\text { - Kesulitan saat menempelkan lem } \\
\text { pada kaleng, memotong } \\
\text { sterofoam } \\
\text { - Kesulitan memotong fiber dan } \\
\text { memasukkannya ke dalam } \\
\text { kaleng } \\
\text { - Kurang ahli dalam menggunakan } \\
\text { peralatan }\end{array}$ \\
\hline 12 & $\begin{array}{l}\text { Apa saran dan masukan perbaikan apa yang dapat } \\
\text { diberikan kepada tim pelaksana PKM terkait kegiatan } \\
\text { pelatihan ini? }\end{array}$ & $\begin{array}{l}\text { - Lebih sering diadakan pelatihan } \\
\text { - Waktu pelaksanaan kurang lama } \\
\text { - Pelatihan ditujukan kepada } \\
\text { pihak sekolah yang benar-benar } \\
\text { membutuhkan (minus } \\
\text { laboratorium) }\end{array}$ \\
\hline 13 & $\begin{array}{l}\text { Jika ada kesempatan pelatihan berikutnya, materi dan } \\
\text { kegiatan apa yang Bapak/lbu inginkan? }\end{array}$ & $\begin{array}{l}\text { Pemuaian, vector, magnet, optic, } \\
\text { dan pesawat sederhana }\end{array}$ \\
\hline
\end{tabular}

Berdasarkan Tabel 1 terlihat munculnya jawaban/respon positif pada semua pertanyaan tertutup, yaitu berupa jawaban paham, tidak sulit, baik sekali, dan sangat perlu. Persentase jawaban positif yang diberikan peserta mencapai > 65\% terdapat pada pertanyaan nomor 1 tentang pemahaman semua alat dan bahan yang dibutuhkan untuk pembuatan Kit Sederhana Termodinamika Kalorimeter (78\%), nomor 2 tentang kesiapan alat dan bahan yang dibutuhkan untuk pembuatan Kit Sederhana Termodinamika Kalorimeter (89\%), nomor 4 tentang kemudahan dalam membuat sendiri alat/kit termodinamika kalorimeter saat tugas diberikan (89\%), nomor 5 tentang pemahaman para guru dalam mengaplikasikannya atau menerapkan Kit Sederhana Termodinamika Kalorimeter dalam percobaan/demonstrasi (67\%), nomor 6 tentang kemudahan dalam mengaplikasikan atau menerapkan sendiri Kit Sederhana Termodinamika Kalorimeter dalam pembelajaran guru di kelas (67\%), nomor 7 tentang manfaat Kit Sederhana Termodinamika Kalorimeter dalam pengukuran dan pembelajaran (67\%), nomor 8 tentang alat/kit termodinamika yang telah dibuat sangat bermanfaat, menunjang dan mendukung pembelajaran Guru di kelas (78\%), dan nomor 10 tentang perlunya dilakukan workshop/pelatihan seperti pembuatan alat di tahun depan (78\%). Hal ini menunjukkan bahwa alat dan bahan yang diperlukan dalam pembuatan alat sangatlah sederhana bahkan dapat ditemukan di sekitar kita yang merupakan barang bekas yang dapat bernilai tinggi dan bermanfaat, apalagi tidak membutuhkan biaya yang mahal.
Pembuatan kit tersebut juga sangatlah mudah, hanya saja dituntut kreativitas guru dalam mengembangkannya. Antusias peserta dalam mengikuti kegiatan ini juga sangat tinggi, yaitu keinginan mengikuti pelatihan yang sejenis berikutnya sangatlah tinggi. Dengan demikian pelatihan ini dapat dinyatakan berhasil dengan baik karena telah memberikan pengetahuan, keterampilan dan kemenarikan bagi pesertanya dengan bukti tingginya antusias peserta untuk kegiatan serupa berikutnya. Namun demikian masih ada beberapa respon sedikit negatif yang diberikan peserta, yaitu jawaban sedikit sulit yaitu pada nomor 2 tentang kesulitan dalam menyiapkan semua alat dan bahan yang dibutuhkan untuk pembuatan kit sederhana termodinamika kalorimeter (11\%), nomor 4 tentang kesulitan dalam melakukan sendiri pembuatan kit sederhana termodinamika kalorimeter saat tugas diberikan (11\%), nomor 6 tentang kesulitan dalam mengaplikasikan atau menerapkan sendiri kit sederhana termodinamika kalorimeter dalam pembelajaran (33\%).

Munculnya respon tersebut bisa diterima secara logis karena diantara peserta yang mengikuti pelatihan ada beberapa guru (kurang lebih 2 orang) memiliki latar belakang pendidikan bukan dari Fisika (Biologi) bahkan ada yang berlatar belakang ilmu sosial (1 orang). Para guru tersebut mewakili sekolah yang bersangkutan karena guru yang kompeten untuk mewakili sekolah tidak bisa hadir mengikuti pelatihan saat itu. Hal ini menunjukkan sisi positif dari pihak sekolah tersebut bahwa komitmen untuk meningkatkan wawasan, pengetahuan dan keterampilan para gurunya tetap dilaksanakan. Namun fakta respon berikutnya 
justru sangat terbalik yakni, meskipun ada kesulitan yang dihadapi para peserta, namun mereka sangat mengharapkan dan menginginkan ada kegiatan sejenis berikutnya dengan berbagai topik pelatihan yang telah mereka sebutkan yakni materi bahasan fisika lainnya. Fakta tersebut mencapai nilai sebesar $78 \%$. Hal ini

\section{SIMPULAN DAN SARAN}

Berdasarkan hasil kegiatan yang telah dilakukan, dapat ditarik suatu simpulan dan beberapa saran pada kegiatan ini, antara lain:

\section{Simpulan}

Simpulkan capaian keberhasilan dalam melakukan kegiatan pelatihan pembuatan kit sederhana termodinamika kalorimeter, yaitu telah dihasilkan dan diperolehnya sejumlah pengetahuan dan ketrampilan bagi peserta sebagai berikut:

- Pengetahuan tentang alat/kit termodinamika seperti kalorimeter, terkait fungsi dan penerapan alat dalam kehidupan sehari-hari (asas Black).

- Pengetahuan tentang pembuatan alat/kit sederhana termodinamika kalorimeter

- Keterampilan dalam membuat alat/kit sederhana termodinamika kalorimeter dengan memanfaatkan bahan-bahan bekas.

- Sikap positif dalam merealisasikan dan menggunakan media pembelajaran di kelas.

- Pengetahuan, pengalaman belajar dan keterampilan membuat dan menerapkan/mengaplikasikan alat/kit hasil pelatihan dalam pembelajaran.

\section{Saran}

Kegiatan pelatihan seperti ini sangat besar manfaatnya dan proses pelatihannya sangat hidup karena peserta banyak melakukan aktivitas untuk berlatih keterampilan dan pengetahuan. Materi pelatihan sangat sesuai dengan kondisi dan kebutuhan guru di lapangan. Namun kegiatan PKM seperti ini membutuhkan dana sangat besar untuk pengadaan barang habis dan konsumsi peserta. Untuk itu dalam menunjukkan adanya kemenarikan pada materi pelatihan yang disampaikan dan pola pendampingan tim pengabdian selama pelatihan, serta kesesuaian antara materipola pelatihan dengan kondisi dan kebutuhan para guru peserta pelatihan.

pelaksanaan pelatihan sejenis berikutnya perlu:

- Mempertimbangkan alokasi waktu, jumlah peserta dan jarak lokasi pelatihan agar biaya yang dikeluarkan bisa diminimalkan.

- Ada kerjasama antara tim PKM dengan mitra PKM dalam pengadaan dana, tidak hanya satu pihak yang menopang pendanaan.

- Lebih mengutamakan peserta dari alumni, selain melaksanakan kewajiban Tri Darma yaitu pengabdian juga sekaligus membina para alumni dalam keprofesionalannya.

- Merintis kerjasama tim PKM Jurusan dengan pihak sekolah dan MKKS untuk pembinaan alumni para guru dan mewadahi kegiatan pengabdian para dosen Jurusan secara periodic dan berkelanjutan

- Menjadikan program rutin tahunan atau agenda rutin kegiatan PKM Jurusan dengan pihak sekolah/MKKS

\section{DAFTAR PUSTAKA}

Keenan. 1980. Kimia untuk Universitas Jilid 1. Erlangga, Jakarta.

Petrucci, Ralph H. 1987. Kimia Dasar Prinsip dan Terapan Modern Jilid 2 Edisi 4. Erlangga, Jakarta.

http://www.mahasiswasibuk.co.cc/1 11 kalori meter.html (diakses pada tanggal 27 November 2014)

http://budisma.net/2015/02/pengertiankalorimeter-dan-kalorimetri.html (diakses pada tanggal 14 Maret 2016)

http://www.academia.edu/8053556/LAPORA $\mathrm{N}$ KALORI METER (diakses pada tanggal 14 Maret 2016) 